\title{
Development and morphology of an unusual nuclear virus of the blue crab Callinectes sapidus
}

\author{
Phyllis T. Johnson \\ National Marine Fisheries Service, Northeast Fisheries Center, Oxford, Maryland 21654, USA
}

\begin{abstract}
The morphogenesis of BFV (Bi-Facies Virus) of the blue crab Callinectes sapidus, is described and discussed. This virus has 2 kinds of development and 2 types of completed particles. The rod-shaped core and its associated structures are similar in the 2 types, but Type A has a double envelope, with the outer envelope being hexagonal in section, while Type B has a single, highly deformable envelope that is roughly elliptical or circular in section. Both envelopes are assembled de novo within the nucleus. Possible relationships of BFV to other viruses are discussed. Its distinctive morphology and development indicate that BFV is the representative of a new family of viruses. It is perhaps related to one or more of the double-stranded DNA viruses of the families Iridoviridae, Poxviridae, Baculoviridae, and Herpesviridae.
\end{abstract}

\section{INTRODUCTION}

Four of the enveloped nuclear viruses of marine invertebrates have been compared to the Herpesviridae by their discoverers. Like most vertebrateinfecting herpesviruses, the 2 smaller ones (100 to 110 $\mathrm{nm}$ in diameter when enveloped) lack envelopes while in the nucleus. They are from the crab Rhithropanopeus harrisii (Payen \& Bonami 1979) and the oyster Crassostrea virginica (Farley et al. 1972, Farley 1978). The 2 larger viruses are both from decapod crustaceans, one from the brachyuran crab Callinectes sapidus (Johnson 1976) and the other from the anomuran crab Paralithodes platypus (Sparks \& Morado 1986). The larger viruses measure approximately 190 to $230 \mathrm{~nm}$ and 140 to $165 \mathrm{~nm}$ respectively, including an outer envelope, which is present on intranuclear particles. They are similar to each other and abundantly distinct from the 2 smaller viruses.

The known geographic distribution, diagnosis, transmission, course of infection, and light microscopy of the Callinectes sapidus virus have been discussed by Johnson $(1976,1978,1983,1984)$. The present article presents observations based on a study of morphogenesis of that virus, which was called HLV (HerpesLike Virus) by Johnson (1978). Examination of further material has shown that the blue crab virus differs significantly from herpesviruses and appears to share some of the morphological and developmental attributes of the
Iridoviridae, Poxviridae, and Baculoviridae. The virus is being redesignated BFV (Bi-Facies Virus) in reference to the fact that it has 2 types of development and 2 final forms.

\section{MATERIALS AND METHODS}

Tissues examined by electron microscopy (EM) were taken from 5 sick or moribund BFV-infected blue crabs. Three of the crabs had been infected in the wild; the other 2 were infected in the laboratory by injection into their hemocoels of BFV-containing hemolymph. The tissues were fixed in $4 \%$ glutaraldehyde in a phosphate buffer, postfixed in $1 \%$ osmium tetroxide, dehydrated in ethanol and propylene oxide, and embedded in Spurr's low viscosity embedding medium (Spurr 1969).

\section{OBSERVATIONS}

BVF infected nuclei of hemocytes and the fixed phagocytes interstitial in the hepatopancreas, and possibly infected nuclei of cells in the hemopoietic tissue, epidermis, and gill epithelium. Infected nuclei were hypertrophied and filled with a rather sparse granular/fibrillar material (Fig. 1). Remaining host chromatin was marginated. Especially during early infection, nuclei sometimes contained small empty ves- 


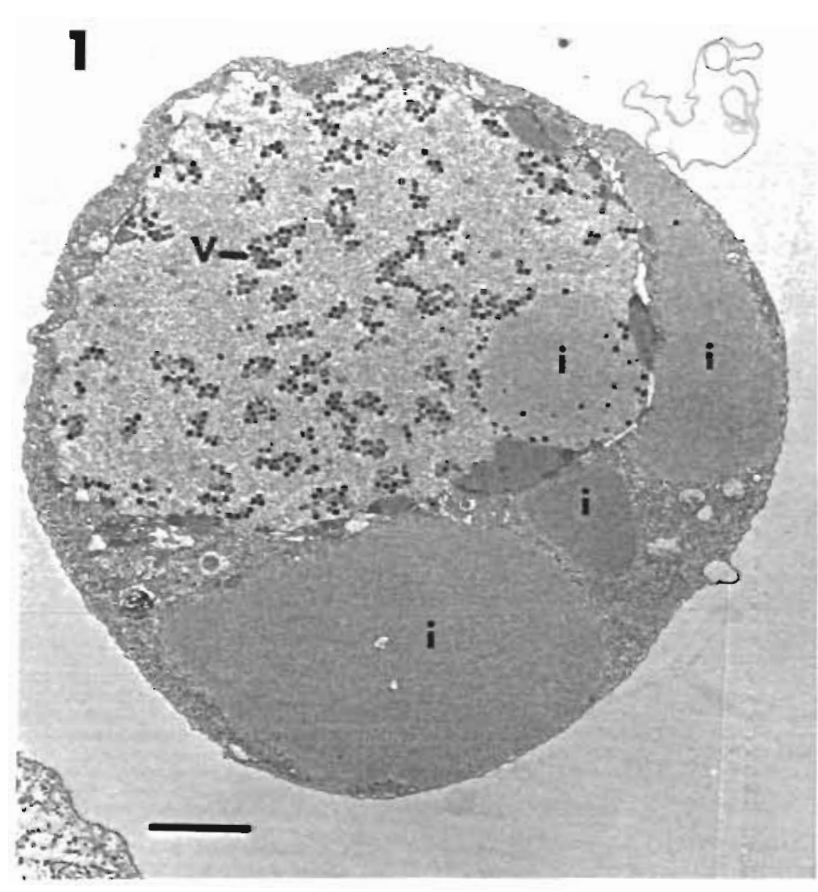

Fig 1 BFV-infected hemocyte Note large inclusions in cytoplasm and corresponding inclusion in nucleus 1 - inclusion $n_{i} V$ vıral partıcles. Bar $=25 \mu \mathrm{m}$

icles that were of variable diameter and occasionally surrounded by more than one membrane, and most infected nuclei contamed electron-dense to opaque inclusions (Fig. 2). Multiple crystalline inclusions were

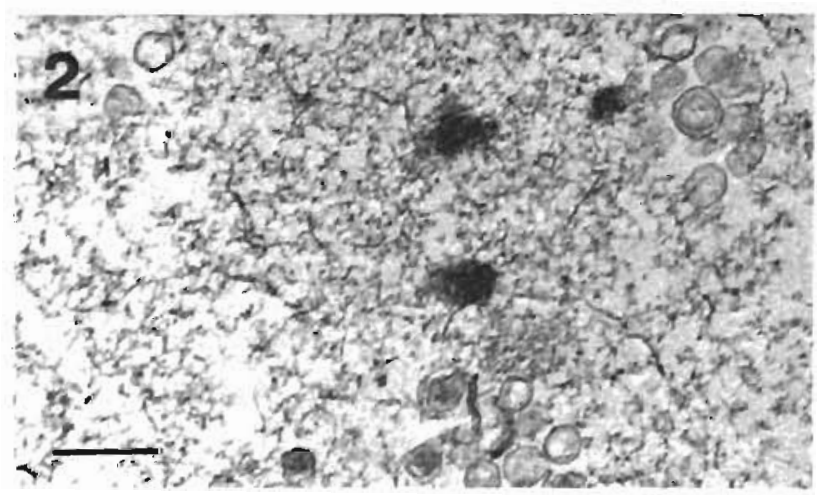

Fig 2 Early BFV infection showing small vesicles and electron-opaque inclusions in the nucleus $B a r=270 \mathrm{~nm}$

present in infected nuclei of 2 crabs (Fig 3). Viral partucles, often at different stages of development, were usually in groups. The relative amount of cytoplasm was reduced. There were mitochondna, free ribosomes (not resolved in Fig 1), and various vesicles, but rough endoplasmic reticulum and the Golgs apparatus were absent. Large, moderately electron-

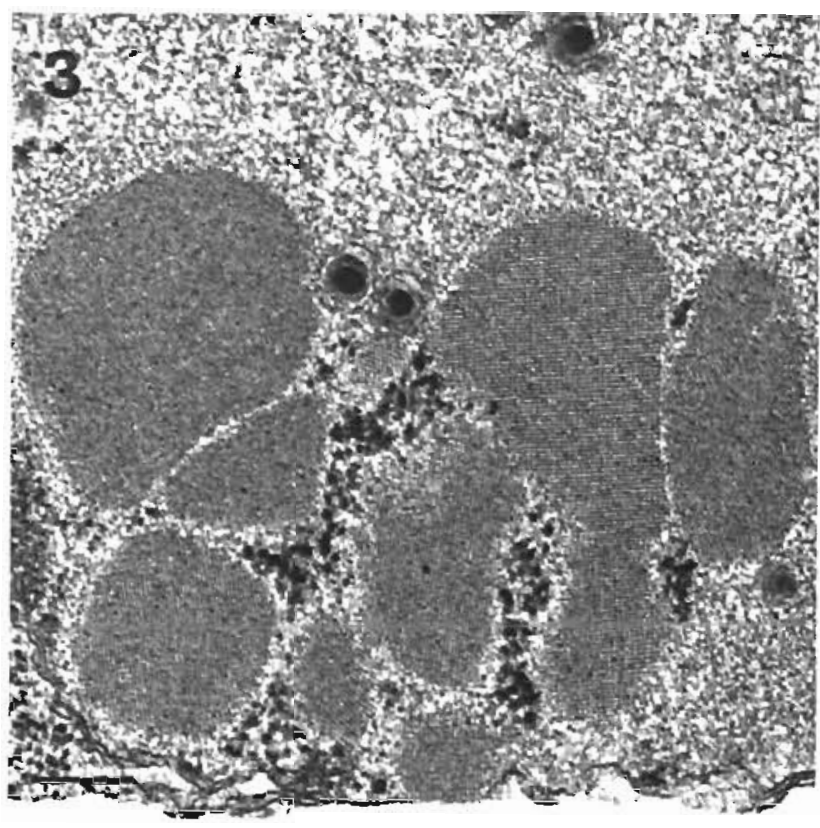

Fig 3 Crystalline inclusions in a BFV-infected nucleus. Particles are Type B. Bar $=270 \mathrm{~nm}$

dense, funely granular inclusions were present in the cytoplasm of almost all infected cells, including those with very early infections. Commonly, material from cytoplasmic inclusions adjacent to the nucleus appeared to have entered through nuclear pores to form similar intranuclear inclusions (Figs. 1 and 7).

There were 2 kunds of completed viral particles, i.e. particles that were morphologically identical whether intranuclear or extracellular. Developmental stages of the 2 types occurred together. Although early stages of both types could be present in a single infected nucleus, there was always a marked preponderance of one type, and usually completed particles were all of the preponderant type.

One or both types of completed particles presumably represented mature, infective virus. One type was surrounded by 1 , and the other by 2 , electron-dense to opaque layers that are being called the outer envelope' and the 'inner envelope' Both envelopes were membranelike, being deformable, especially the inner one. Each was 7 to $10 \mathrm{~nm}$ thick, with the outer envelope sometimes slightly thicker and more nearly opaque than the inner one. There were indications that both envelopes were trilaminar (Fig. 4A). Icosahedral symmetry of the outer envelope was indicated by the presence of both 6 - and 5-sided profiles

The 2 types of particles are being designated 'Type $A^{\prime}$, which has both inner and outer envelopes, and 'Type B, which is surrounded by only the inner envelope (Figs 4 and 5). The inner envelope of mature Type A particles usually conformed more-orless to the hexagonal shape of the outer envelope. The 
Fig. 4. Morphogenesis of Type A. (A) Stage 1, montage showing early and later steps in envelope development; arrow indicates apparent trilaminarity of inner and outer envelopes. (B) Stage 2. (C) Stage 3. (D) Stage 4, sagittal and transverse sections. (E) Stage 5, sagittal and transverse sections. (F) Developmental stages in situ. Material inside the envelope of immature particles of both Type A and Type B appears to be made up of similar subunits with punctate centers (arrows). C core; cyl: cylinder; E: inner and outer envelopes; EDS: electron-dense sphere; 1 to 5: Stages 1 to 5. (A to E) Bar $=93 \mathrm{~nm}:(\mathrm{F})$ bar $=270 \mathrm{~nm}$
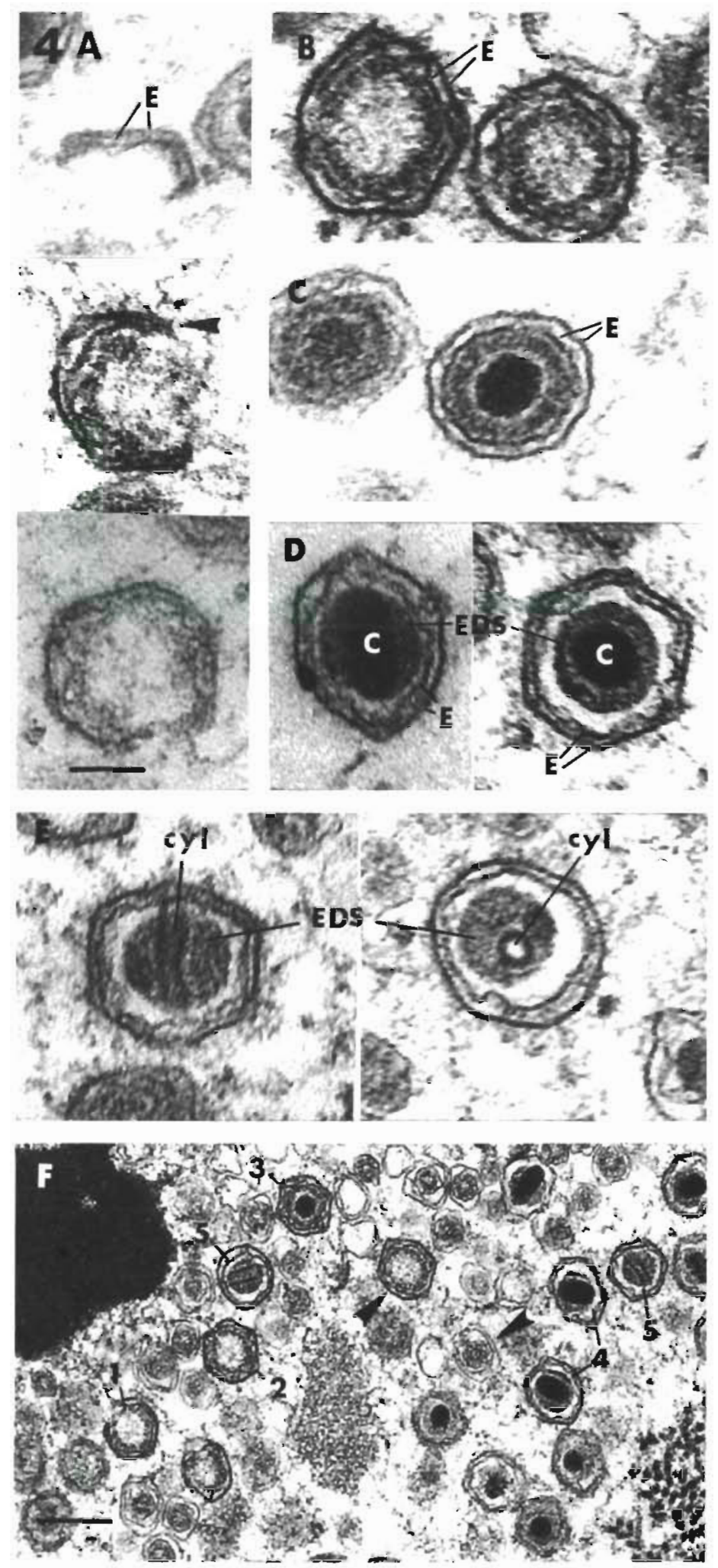

single (inner) envelope of Type B was irregular and tended to be roughly elliptical or circular in section. The diameter of enveloped Type B particles corresponded to that of the inner envelope of Type A parti- cles (Table 1). Inside the envelope(s) of completed particles of both types there was a short, rod-shaped, electron-opaque core surrounded by an electrondense sphere (EDS) (Figs. 4D and 5C). Based on its 

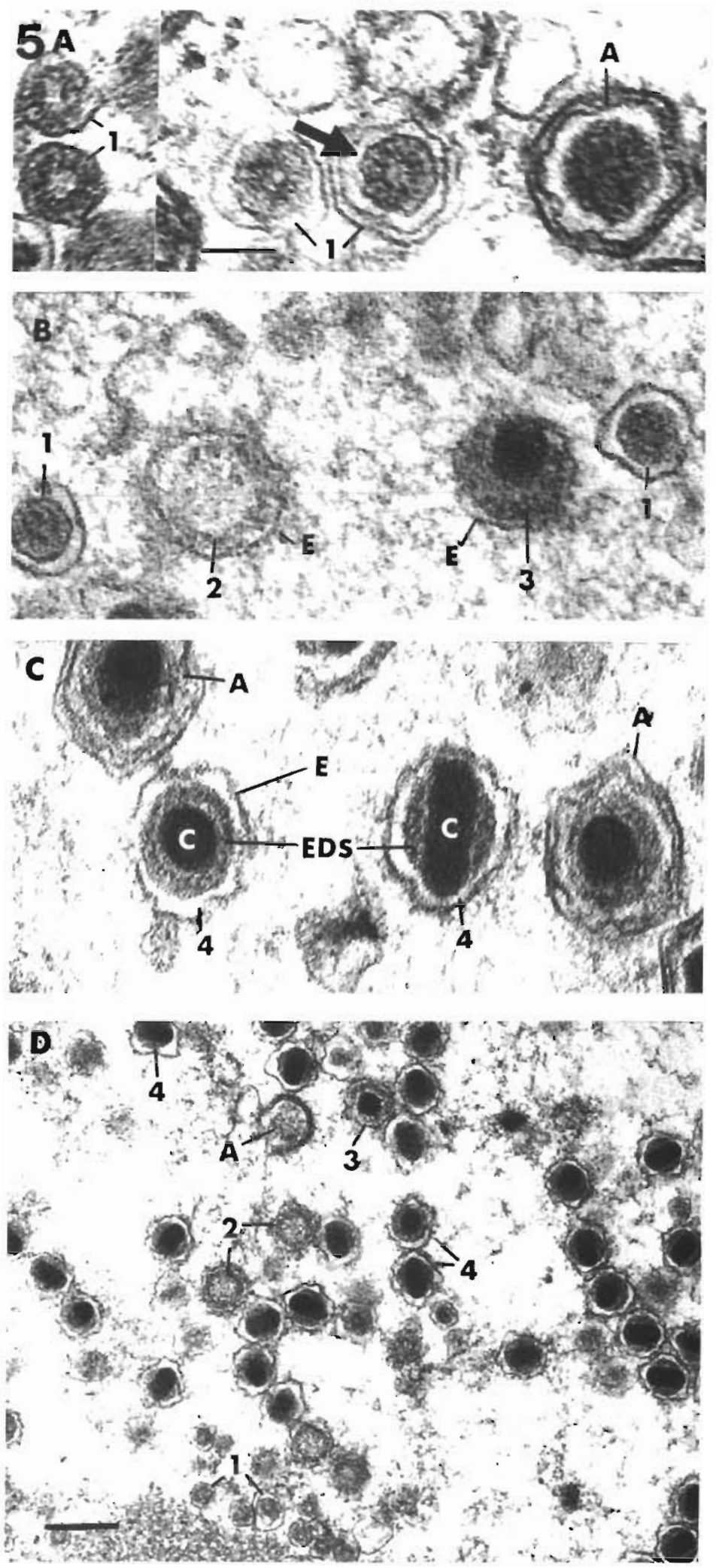

Fig 5 Morphogenesis of Type B. (A) Putative Stage 1 , montage showing particles with and without associated membrane Note subunits with punctate centers (arrow), also present in a Type A particle included for companson (B) Stages 1 to 3. (C) Stage 4, transverse and sagittal sections. Stage 4 particles of Type A are also present (D) developmental stages in situ. A Stage 1 particle of Type $A$ is also present. A: Type $A_{i} C:$ core $E$ inner envelope; EDS: electron-dense sphere; 1 to 4 : Stages 1 to 4 (A to C) Bar $=93 \mathrm{~nm}$; (D) bar $=270 \mathrm{~nm}$

staining characteristics and its development (described below), the core was assumed to contan the viral nucleoprotein. The ends of the core were rounded and either flush with the surface of the EDS or extending somewhat beyond it. The core of Type B particles tended to be longer and thinner than that of 
Table 1 Mean (range) least and greatest diameter of Type A and Type $B$ envelopes. Measurements of the hexagonal outer envelope were from face to face (least) and point to point (greatest)

\begin{tabular}{|lcc|}
\hline Structure & Type A & Type B \\
\hline $\begin{array}{l}\text { Inner } \\
\text { envelope }\end{array}$ & $164 \times 199-176 \times 163-217)$ & $(163-196 \times 163-217)$ \\
Outer & $197 \times 233$ & - \\
envelope & $(190-203 \times 203-257)$ & \\
\hline
\end{tabular}

Type A (Table 2), and the EDS of Type B was sometimes elliptical in section (Fig. 5C).

Morphogenesis was initiated differently in the 2 types, but the later stages of core and EDS formation appeared to be similar. The first structure visible during morphogenesis of Type A was a partial hexagon made up of 2 layers that were interpreted as being the developing outer and inner envelopes (Stage 1) (Fig. 4A). When cut at an appropriate angle, electron-dense material that appeared along the inner surface of the partial hexagon during development (Stage 2) (Fig. 4B) consisted of lucent, $30 \mathrm{~nm}$ discs with dense, punctate centers (Figs. $4 \mathrm{~F}$ and $5 \mathrm{~A}$ ). In particles whose envelopes approached complete closure, there were scattered granules in the center and the marginal material appeared to have migrated toward the center, becoming denser and amorphous. At this point or before, the core appeared in the central part (Stage 3) (Fig. 4C). In the completed particle, all the internal material was condensed into the spherical EDS, which closely surrounded the core, and the envelopes were closed (Stage 4) (Fig. 4D). One heavily infected nucleus was unusual because it contained numerous examples of Type A particles in all stages of development. In this nucleus many Type A particles had an empty cylinder about $40 \mathrm{~nm}$ in diameter within the EDS rather than an electron-opaque core (Stage 5) (Fig. 4E). The wall of the cylinder was electron-opaque. Rarely, similar cylinders were present in particles in more lightly infected nuclei.

The earliest stage seen in sections that was unequivocally a part of Type $B$ development consisted of a partial or complete envelope with dense material adherent to its inner surface (Stage 2) (Fig. 5B). This stage was sometimes partially surrounded by further membrane fragments and looked like a developing Type A particle except that it lacked a hexagonal outer envelope. The remainder of Type B development paralleled that of Type A, and ended with a core and EDS surrounded by a single envelope (Stage 4) (Figs. $5 \mathrm{C}, \mathrm{D})$. The beginning of Type $\mathrm{B}$ development might have involved a spherical to angulate structure, about $90 \mathrm{~nm}$ in diameter, that contained subunits with punctate centers similar to those seen in developing Type $A$ (putative Stage 1) (Fig. 5A). This particle had a $5 \mathrm{~nm}$ thick, opaque, outer margin that probably was a membrane (see 'Discussion'). The $90 \mathrm{~nm}$ particle was sometimes partially enclosed in one or more additional fragments of membrane. Developmental stages between the $90 \mathrm{~nm}$ particle (putative Stage 1) and the larger particle (Stage 2) were not observed. Stages 2 and 3 were uncommon, but putative Stage 1 particles were numerous in most infected nuclei, including ones that had Type $A$ as the dominant form.

BFV particles in the nucleus of a cell in tissue that

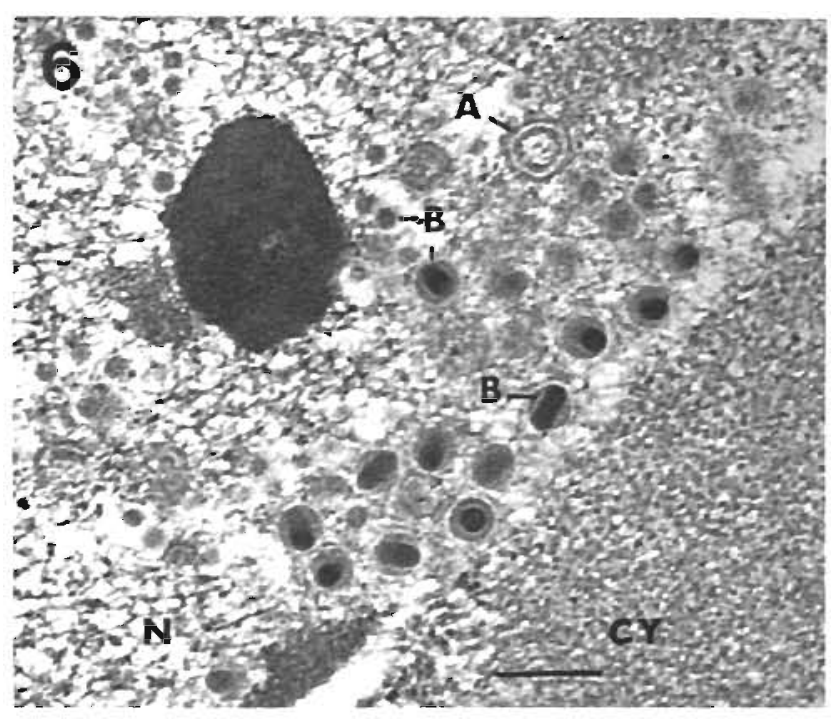

Fig. 6. BFV particles in tissue damaged during fixation. Note lack of: nuclear membranes, envelopes of Stage 4 Type B, opaque margin around $90 \mathrm{~nm}$ particles, and inner envelope of immature Type A. A: Type A; B: Type B; CY: cytoplasm; N: nucleus. $\mathrm{Bar}=270 \mathrm{~nm}$

Table 2. Sizes of BFV cores and cytoplasmic rods

\begin{tabular}{|lccc|}
\hline Particle & $\begin{array}{c}\text { Mean diameter (range) } \\
(\mathrm{nm})\end{array}$ & $\begin{array}{c}\text { Mean length (range) } \\
\text { (nm) }\end{array}$ & $\begin{array}{c}\text { Mean volume } \\
\text { (ul) }\end{array}$ \\
\hline Type A & $75(69-85) n=14$ & $138(127-149) n=13$ & 612 \\
Type B & $70(57-77) n=17$ & $156(137-185) n=12$ & 600 \\
Rod & $61(49-74) n=16$ & $218(180-254) n=13$ & 637 \\
\hline
\end{tabular}


had been accidentally exposed to icewater during glutaraldehyde fixation were smaller than usual. The majority were Type $B$. The envelope of completed Type $B$ particles was missing, and the $90 \mathrm{~nm}$ particles lacked the opaque outer margin (Fig. 6). Immature Type A particles in the same nucleus lacked the inner envelope but had retained the outer one. Internal host-cell membranes were missing, but the plasma membrane was present.

Completed and developing particles of both types were occasionally present in the cytoplasm of cells with infected nuclei, occurring both in the finely granular inclusions described earlier, and free in the ground substance. Entrance of Type A particles into cells may have been by viropexis (phagocytosis); completed Type A particles were founc iwice in cytopiasmic vesicles in normal hemocytes. Release of both types of BFV particles was by lysis of infected cells

There were many more Type A than Type B particles in the extracellular space, although more than half the infected nuclei examined had Type B as the preponderant form. At times, singly enveloped degenerate

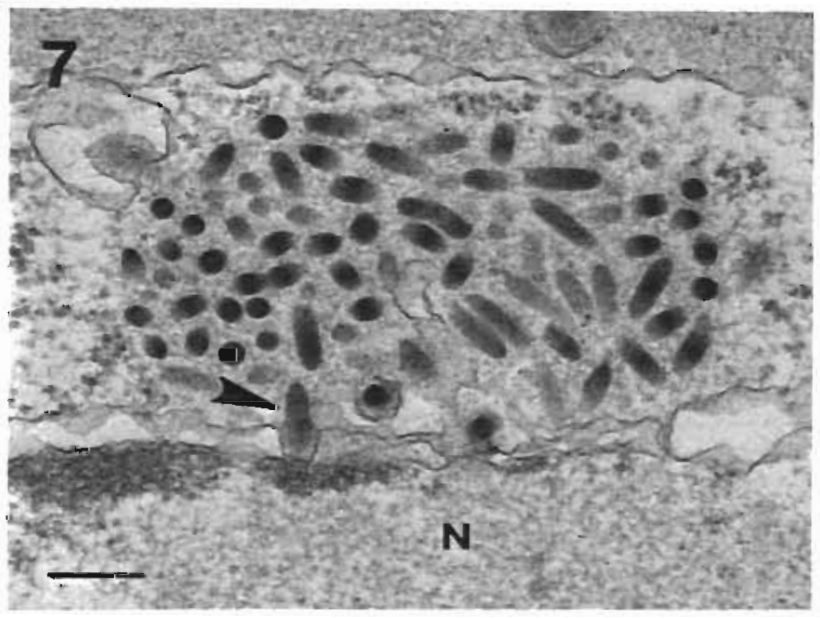

Fig. 7. Cytoplasmic rods in a cell with an early BFV infection One rod is associated with a nuclear pore (arrow). Granular material like that surrounding the rods is present in the nucleus. $\mathrm{N}$ : nucleus. $\mathrm{Bar}=270 \mathrm{~nm}$

particles, presumed to be Type $B$, were present extracellularly, intermixed with Type A particles of normal appearance.

There were groups of electron-opaque rods, approximately $60 \times 220 \mathrm{~nm}$, in the cytoplasm of many infected cells (Table 2, Fig. 7). Rods also occurred in the cytoplasm of hemocytes with nuclei of normal appearance. They were either embedded in the large, finely granular, cytoplasmic inclusions common in infected cells, or in a similar matrix that encompassed only the rods. When the matrix was next to the nucleus, material similar to it was usually observed in adjacent areas of the nucleus (Fig. 7). When rods were next to cytoplasmic vesicles they tended to protrude into them, but it was unlikely that the rods were budding into the vesicles because completely enveloped rods did not occur in the cytoplasm, and extracellular rods, which were

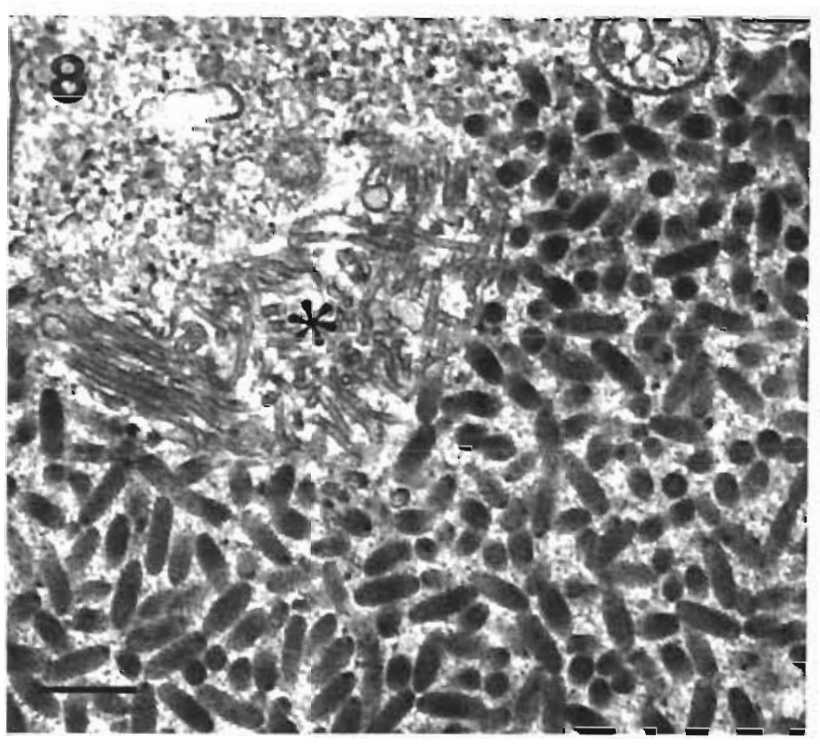

Fig. 8. Mass of rods in material associated with a fixed phagocyte. A small rhabdolike virus is also present (asterisk). Bar = $270 \mathrm{~nm}$

found in groups within cellular debris and in material associated with the fixed phagocytes, never had envelopes (Fig. 8). Rods were sometimes more or less perpendicular to nuclear pores (Fig. 7), but only once was a free rod (or BFV core?) observed within a nucleus. It was unenveloped and in a nucleus with Type B as preponderant form.

\section{DISCUSSION}

There had been shrinkage of the EDS in the BFVinfected tissue originally studied by Johnson (1976) because the tissue had been embedded in paraffin and re-embedded in resin for electron microscopy. The ends of the core usually extended well beyond the surface of the EDS in this tissue, leading to the erroneous description of the EDS as a torus rather than a sphere. This misconception was repeated by Johnson (1983, 1984).

The morphology and development of BFV differ considerably from those of the Herpesviridae. Herpesvirus nucleoprotein is contained in an electron-opaque torus or annulus that is external to a more-or-less cylindrical. filamentous, and less electron-dense to electron-lucent structure ('core') that occupies the center of the particle (Fig. 9) (Furlong et al. 1972, Nazerian 1974, Roizman \& 
BFV
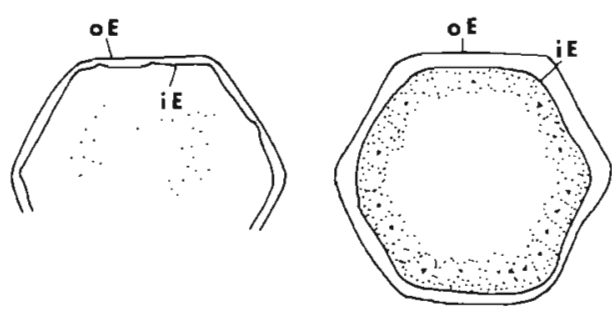

1

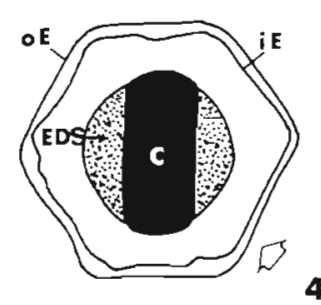

4

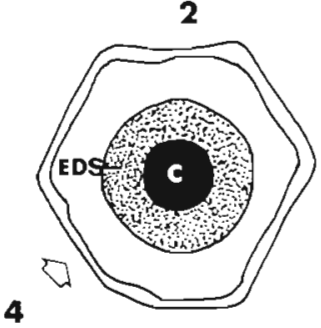

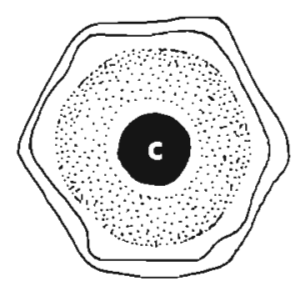

3

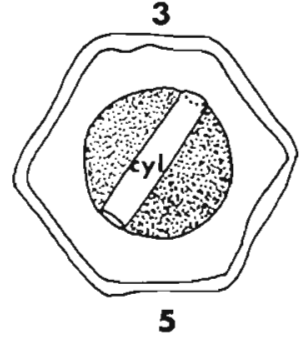

Herpesvirus

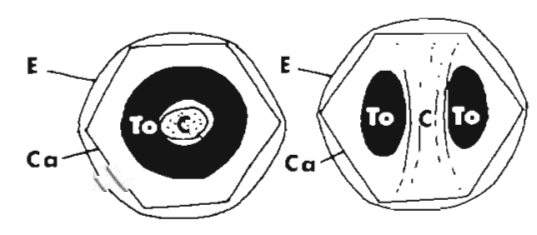

Type A

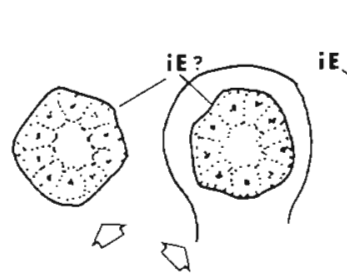

$1 ?$

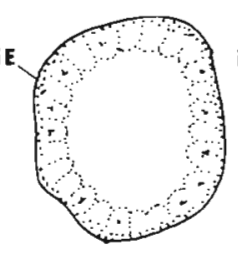

2

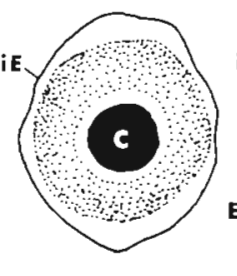

3

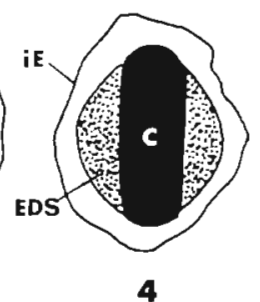

Fig. 9. Mature particles of herpesvirus and BFV, with a diagrammatic interpretation of morphogenesis in Types A and B. Developmental stages of BFV shown are numbered 1 to 5 (see text and Figs. 4 and 5). C: core; Ca: capsid; cyl: cylinder; E: envelope; EDS: electron-dense sphere; $i E$ : inner envelope; oE: outer envelope; To: torus

\section{Type B}

Furlong 1974, Perdue et al. 1976, Wildy 1986). The electron-opaque rod-shaped core of BFV (which contains the viral nucleoprotein as judged by its staining and developmental characteristics) is situated centrally and occupies the position of the quasicylindrical electron-lucent 'core' of herpesvirus. It is surrounded, not by a nucleoprotein-containing torus, but by the electron-dense, roughly spherical EDS. Unlike herpesvirus, BFV does not have an icosahedral capsid external to its core and internal to its envelope. The EDS occupies that position. Unlike known vertebrate-infecting herpesviruses (with the possible exception of Herpesvirus saimiri [Heine et al. 1971]), BFV does not gain its envelope(s) by budding through a host-cell membrane. Instead, the envelope(s) are formed de novo within the nucleus.

BFV and baculoviruses are similar in that the cores of both are rod-shaped. The empty cylinder that occasionally occupies the position of the core in the EDS of BFV Type A particles apparently represents the container for the viral nucleoprotein and thus is homologous or analogous to the capsid of baculovirus.

The EDS has no obvious counterpart in the iridoviruses, but poxviruses have lateral bodies which form from material that condenses onto the DNA-containing core, and herpesviruses have a variably dense substance between the capsid and envelope that has been called the tegument (Roizman 1982). Baculoviruses also often have an electron-dense particulate material between the envelope and the capsid, and there are complex interactions between the nucleocapsid and the particles making up the dense material (Kawamoto et al. 1977).

The inner envelope of BFV has attributes in common with internal host-cell membranes, and presumably is a membrane itself, because all these morphologically similar structures disappeared in tissues damaged during fixation. The electron-opaque membranelike structure that closely surrounded the $90 \mathrm{~nm}$ particle which is conditionally associated with early development of Type B also was lost from the damaged tissue. The outer envelope of Type A remained (like the plasma membrane) possibly because both the outer envelope and the plasma membrane contained proteins that prevented their dispersal.

Assembly of BFV Type A outer and inner envelopes 
appears similar to assembly of the protein-containing icosahedral envelope (usually called the 'shell') and inner or core membrane of iridoviruses (Stoltz 1971 . 1973). It also resembles assembly of the protein-containing envelope of some entomopoxviruses (Granados \& Roberts 1970, Bergoin \& Dales 1971, Granados 1973 1981). Electron micrographs in the papers cited above show that the envelope (and the iridovirus inner or core membrane, which may become applied to the core in mature particles) of certain species of both viral groups are derived from 2 trilaminar elements which are formed de novo, and have the appearance and dimensions of unit membranes (Granados \& Roberts 1970, Bergoin \& Dales 1971, Stoltz 1971, 1973, Stoltz \& Summers 1972). However, other species of the Iridoviridae and Poxviridae appear to derive their envelope (and core membrane in the case of iridoviruses) in association with only one trilaminar element, leading some to conclude that probably only one unit membrane is involved in all cases (Stoltz \& Summers 1972, Stoltz 1973). The possibility that either 1 or 2 trilaminar membranelike elements might be involved in morphogenesis of iridoviruses and poxviruses, depending on the species or group, perhaps should not yet be ruled out because morphogenesis of another virus, BFV, can occur in the presence of either 1 or 2 membranelike elements.

The protein in the icosahedral envelope of iridoviruses takes the form of triangular lattices called trisymmetrons (Wrigley 1970, Stoltz 1971, 1973). The envelope of iridoviruses is fairly rigid, but deformability of BFV's outer envelope is considerable, which suggests the putative protein determining its icosahedral shape cannot be so rigidly constructed, and may be of a different type. Other proteins that form viral envelopes of definite shapes, as in poxviruses, do not form polyhedra; but there is a protein (not based on trisymmetrons) that does form polyhedra in a non-viral system. The protein is clathrin, which together with a smaller polypeptide forms triskelions that make a polyhedral framework of hexagons and pentagons over the membrane of coated vesicles (Alberts et al. 1983)

The diameter and length of the electron-opaque cytoplasmic rods commonly present in BFV-infected cells are partially within the range of BFV cores, and the rods were always associated with what was probably a BFV-induced protein. Similar cytoplasmic rods were never seen in tissues of blue crabs infected with any of the other blue-crab viruses or in tissues from virus-free crabs. This suggests that the rods are in some way associated with development of BFV, but the possibility that they represent a different virus has not been ruled out.

Morphogenesis of both types of BFV particles apparently takes place very rapidly, because intermediate stages were rare except in the one unusually heavily infected nucleus, where all stages of Type A assembly were well represented. Probably some of the materials necessary for assembly had been depleted and were no longer sufficient for completion of all the particles present. In a somewhat similar case, Tralka et al. (1977) found that particles at intermediate stages of assembly of Herpesvirus saimiri accumulate, and morphogenesis is slower, in a cell line that only marginally supports this virus' replication. They said that the slowdown of development gave them information about morphogenesis of $\mathrm{H}$. saimiri that could not be obtained by study of infection in highly permissive host cells. The same was true of BFV and the heavily infected cell.

The general paucity of Type $\mathrm{B}$ in the extracellular space and presence of degenerating extraceillular Type $B$ particles suggest that it is more sensitive to adverse conditions that may exist outside the cell than is Type A. Possibly Type $B$ is an aberrant form and not infective, although it should be remembered that more than half the infected nuclei inspected during this study had Type $B$ as the preponderant form.

In conclusion, BFV is probably a representative of an undescribed family of viruses. Its relatives may be among the double-stranded DNA viruses of the families Iridoviridae, Poxviridae, Baculoviridae, and Herpesviridae, but BFV differs markedly from known species of all these groups. The virus that was found in the antennal-gland and bladder epithelia of Paralithodes platypus by Sparks \& Morado (1986) is undoubtedly related to BFV. Apparently only particles with 2 envelopes, and thus comparable to Type $A$ of BFV, were observed by those authors.

Acknowledgements. I am grateful to R. R. Granados, Boyce Thompson Institute, Cornell University, Ithaca, New York, for his helpful and generously given advice, and to J. Swann of the Oxford Laboratory, who provided editorial assistance and typed the manuscript.

\section{LITERATURE CITED}

Alberts, B., Bray, D., Lewis, J., Raff, M., Roberts, K., Watson, J. D (1983). Molecular biology of the cell. Garland, New York

Bergoin, M., Dales, S. (1971). Comparative observations on poxviruses of invertebrates and vertebrates. In: Maramorosch, K., Kurstak, E. (eds.) Comparative virology, Chap. 6. Academic Press, New York, p. 169-205

Farley, C. A. (1978). Viruses and viruslike lesions in marine mollusks. Mar. Fish. Rev. 40 (10): 18-20

Farley, C. A., Banfield, W. C., Kasnic, G. Jr, Foster, W. S. (1972). Oyster herpes-type virus. Science 178: 759-760

Furlong, D., Swift, J., Roizman, B. (1972). Arrangement of herpesvirus deoxyribonucleic acid in the core. J. Virol. 10: $1071-1074$

Granados, R. R. (1973). Insect poxviruses: pathology, morphology, and development. Miscell. Publ. Entom. Soc. Am. 9 $73-94$ 
Granados, R. R. (1981). Entomopoxvirus infections in insects. In: Davidson, E. W. (ed.) Pathogenesis of invertebrate microbial diseases, Allanheld, Osmun, Totowa, New Jersey, p. 101-126

Granados, R. R., Roberts, D. W. (1970). Electron microscopy of a poxlike virus infecting an invertebrate host. Virology 40 : $230-243$

Heine, U., Ablashi, D. V., Armstrong, G. R. (1971). Morphological studies on Herpesvirus saimiri in subhuman cell cultures. Cancer Res. 31: 1019-1029

Johnson, P. T. (1976). A herpeslike virus from the blue crab, Callinectes sapidus. J. Invertebr Pathol. 27: 419-420

Johnson, P. T. (1978). Viral diseases of the blue crab, Callinec tes sapidus. Mar. Fish. Rev, 40 (10): 13-15

Johnson, P. T (1983). Diseases caused by viruses, rickettsiae, bacteria, and fungi. In: Provenzano, A. J. (ed.) The biology of Crustacea, Vol. 6. Academic Press, New York, p. 1-78

Johnson, P. T. (1984), Viral diseases of marine invertebrates. Helgoländer Meeresunters. 37:65-98

Kawamoto, F., Kumada, N., Kobayashi, M. (1977). Envelopment of the nuclear polyhedrosis virus of the oriental tussock moth, Euproctis subflava. Virology 77: 867-871

Nazerian, K. (1974). DNA configuration in the core of Marek's disease virus. J. Virol. 13: 1148-1150

Payen, G. G., Bonami, J.-R. (1979). Mise en evidence de particles d'allure virale associées aux noyaux des cellules mesodermiques de la zone germinative testiculaire du crabe Rhithropanopeus harrisï (Gould) (Brachyoure, Xanthide). Rev. Trav. Inst. Pêch. marit. 43: 361-365

Perdue, M. L., Cohen, J. C., Randall, C. C., O'Callaghan, D. J.
(1976). Biochemical studies of the maturation of herpesvirus nucleocapsid species. Virology 74 : 194-208

Roizman, B. (1982). The family Herpesviridae: general description, taxonomy, and classification. In: Roizman, B. (ed.) The herpesviruses, Vol. 1 Plenum Press, New York, p. 1-23

Roizman, B., Furlong, F. (1974). The replication of herpesviruses. In: Fraenkel-Conrat, H., Wagner, R. R. (eds.) Comprehensive virology, Vol. 3. Plenum Press, New York, p. $229-403$

Sparks, A. K., Morado. J. F. (1986). A herpes-like virus disease in the blue king crab Paralithodes platypus. Dis. aquat. Org. 1: 115-122

Spurr, A. R. (1969). A low viscosity epoxy resin embedding medium for electron microscopy. J. Ultrastruct. Res. 26: $31-43$

Stoltz, D. B. (1971). The structure of icosahedral cytoplasmic deoxyriboviruses. J. Ultrastruct. Res. 37: 219-239

Stoltz, D. B. (1973). The structure of icosahedral cytoplasmic deoxyriboviruses. II. An alternative model. J. Ultrastruct. Res. 43: 58-74

Stoltz, D. B., Summers, M. D. (1972). Observations on the morphogenesis and structure of a hemocytic poxvirus in the midge Chironomus attenuatus. J. Ultrastruct. Res. 40: $581-598$

Tralka, T. S., Costa, J., Rabson, A. (1977). Electron microscopic study of herpesvirus saimiri. Virology 80: 158-165

Wildy, P. (1986). Herpesvirus. Intervirology 25: 117-140

Wrigley, N. G. (1970). An electron microscope study of the structure of Tipula iridescent virus. J. gen. Virol. 6: $169-173$

Responsible Subject Editor Dr J. E. Stewart: accepted for printing on December 31, 1987 